\title{
Disciplinaridade e construção interdisciplinar do saber ambiental
}

\section{Disciplinarity and the interdisciplinary construction of environmental knowledge}

\author{
Dimas FLORIANI ${ }^{*}$
}

\section{RESUMO}

\begin{abstract}
Natureza e Sociedade mantêm diversos e diferentes mecanismos de trocas e de interações. A maneira de como ocorrem podem ser percebidos, representados e explicados pelos sistemas de conhecimento (científico ou não). Os sistemas culturais das sociedades contemporâneas podem valorizar ou desvalorizar as interpretações que por sua vez reforçam ou debilitam as lógicas das práticas interventoras sobre os ecossistemas e as sociedades que com eles interagem. Questionar esses distintos processos de conhecimento e de intervenção na realidade é um dos objetivos do presente artigo.

Palavras-chave: interdisciplinaridade; sistemas cognitivos; cultura, meio ambiente e desenvolvimento.
\end{abstract}

\begin{abstract}
Nature and Society are connected by many and differents mecanisms. The means that they appear depend on the knowing, as much scientific as common sense one. The cultural systems of contemporary societies can take for granted or not the several interpretation about the meaning of the reality and its results. Discuss these differents views and matters are the main focus of this paper.

Key-words: interdisciplinarity; knowing systems; culture, environment and development.
\end{abstract}

\section{Introdução}

Presumimos aqui, para efeito de nosso debate, que o real é uma entidade reconhecível de alguma maneira e que a disposição atribuída a ele, sobre o que constitui o conhecimento, é um ato deliberado de construção e de disputas pela apropriação de sentidos. Aceitamos também o fato de que o sentido do mundo encontra sua expressão em um sistema de signos, imagens, ruídos, cores, sabores e sensações organizados em forma de linguagem. Sistemas lógicos (pensamentos) e existenciais (emoções) coexistem separados ou em interação.

Um sistema de idéias ocorre e decorre de um contexto de longa duração, de trocas e conflitos de significação de objetos materiais, crenças, valores, interesses, funções

\footnotetext{
* Doutor em Sociologia e Professor Titular do Departamento de Ciências Sociais da UFPR. Professor e ex-Coordenador do Doutorado em Meio Ambiente e Desenvolvimento.
} 
consubstanciadas em sistemas sociais que desenvolvem práticas materiais de produção, apropriação e reprodução das condições de existência de uma determinada organização social.

Embora indissociáveis do conjunto, no plano concreto, as diversas esferas de um sistema social podem ser decompostas intelectualmente, permitindo, assim, perceber suas lógicas particulares, bem como suas conexões com as demais instâncias da realidade.

Diante da indagação de como uma dada organização social mantém um sistema de trocas com seu meio, (ecossistema) é possível entender os processos de interação com a natureza sob diversos ângulos:

a - pelo sistema das práticas econômicas (apropriação da natureza, como recurso material e práticas de intervenção tecnológicas, visando à produção de determinados produtos); o sistema das trocas internas e externas entre os indivíduos e grupos sociais (sistema monetário ou não que indica o grau de desenvolvimento da divisão social do trabalho), condicionantes do sistema de consumo;

b - pelo sistema das práticas simbólicas (cultura) de conhecimento e reconhecimento da realidade, indicando as modalidades de produção social do discurso; do sistema lógico e cognitivo; da comunicação; dos saberes espontâneos, culturalmente arraigados e em metamorfose; da organização do imaginário e dos vínculos com o sagrado e com o profano e com o seu inconsciente, ousaria dizer;

c - pelo sistema de poder e de rede da organização sociopolítica, indicando o tipo de institucionalização das práticas sociais e de poder entre indivíduos e grupos e as respectivas autonomias e/ou vínculos entre sistemas políticos, religiosos, econômicos, cognitivos, comunicacionais, afetivos etc.

A transposição desse esquema de representação cognitivo para um quadro de referência atual coloca-nos diante de uma situação em que a explicação das dinâmicas observadas decorrem dos marcos cognitivos do observador, imerso no próprio sistema social. Tanto o sistema de conhecimento classificatório como o explicativo decorrem do sentido extraído do sistema das práticas simbólicas institucionalizadas.

Contudo, os sistemas de pensamento das sociedades contemporâneas modernas não decorrem automaticamen- te de uma matriz fixa e imutável, mas de uma plasticidade adaptativa, emergente do campo de disputas simbólicas de sentido e de significação do mundo.

Pode-se representar o real de distintas e múltiplas maneiras, pelas suas partes ou pelo seu todo, revelando com isso diversas estratégias de identificação de matrizes cognitivas, objeto de disputas e motivações divergentes pertencentes a constelações de interesses e avaliações diferenciadas.

Dependendo do seu lugar social e cultural, assumido e reivindicado, o observador faz apelo a um sistema de reconhecimento do mundo, apoiado em valores e crenças de seu campo cognitivo. Ora, o sistema cognitivo das sociedades atuais (suas práticas e seus pensamentos) busca predominantemente sua legitimidade no sistema científicotecnológico, definido por alguns como racionalidade instrumental, em oposição às racionalidades alternativas ou ambientais, quando se trata de situar o debate em torno da relação sociedade-natureza.

É no interior desse contexto que buscamos entender as estratégias emergentes das novas práticas e dos novos sentidos interdisciplinares.

\section{As ciências: sistemas classificatórios, obstáculos e novas alianças}

O início dos debates em torno da interdisciplinaridade completa já algumas décadas e pode-se dizer que suas origens estão localizadas nos anos 60 e 70. Embora fundamental para compreender o contexto de sua emergência, não nos ocuparemos aqui da sua reconstituição, uma vez que sua aplicação pode estar associada a diversos domínios de conhecimento conexos: ciências cognitivas, lógica, teoria da informação, biologia, entre outras.

As tentativas de formulação do caráter da interdisciplinaridade e da pertinência de sua aplicação dependiam do entendimento teórico sobre o estatuto das ciências, bem como da aplicabilidade das metodologias interdisciplinares decorrentes da aproximação que algumas ciências faziam sobre um mesmo tema.

Ora, pode-se afirmar que tanto o estatuto teórico das ciências, como o campo de aplicabilidade das metodologias interdisciplinares variam conforme o contexto científicotecnológico e a conseqüente cultura que a sociedade possui ou desenvolve sobre as complexas interfaces existentes entre o sistema científico e o sistema social. 
Por sua vez, diferentes contextos científico-tecnológicos desenvolvem epistemologias diferenciadas que influenciam e são influenciadas pelo debate que as sociedades mantêm e desenvolvem em torno de temas cruciais sobre a natureza, a sociedade, a religião, os valores, a política...

As diversas ciências são chamadas a testemunharem e opinarem sobre uma variedade de temas, mobilizando a opinião das comunidades científicas, da mídia, das agências públicas e privadas produtoras ou controladoras do conhecimento científico.

A eclosão do diálogo de saberes científicos é a expressão do conteúdo cultural latente no sistema de representação das ciências. Possivelmente, o reconhecimento por parte da sociedade e das comunidades científicas das dificuldades em propiciar respostas confiáveis sobre um conjunto de problemas, dentre os quais os socioambientais, tem favorecido a emergência de novas disposições e questionamentos sobre a inadequação da antiga cartografia classificatória das ciências que dispunham a realidade à sua semelhança e aos seus interesses particulares.

Há quase 30 anos, Prigogine (1984) antecipava o cenário para os tempos atuais, assumindo claramente a posição de que os valores em jogo da metamorfose da ciência não são todos de ordem científica; que a existência da ciência e o conteúdo das teorias científicas podem ter algo a ver com as relações que os homens mantêm com o mundo natural; que a ciência faz parte do complexo de cultura a partir do qual, em cada geração, os homens tentam encontrar uma forma de coerência intelectual; que doravante fazer ciência seria renovar concepções das relações dos homens com a natureza, como prática cultural.

Assim, a ciência se reconhece como parte integrante da cultura no seio da qual se desenvolve; mas, complementarmente, ao reconhecer que essa cultura científica se define como obra de seres inscritos no mundo que eles exploram e no qual nada da natureza poderia aparecer de estranho para quem a descreve, a natureza aparece também como não feita para nós e não entregue à nossa vontade.

Ora, todas essas novas disposições de reconhecimento da natureza e dos sistemas explicativos do mundo tendem a predispor um caráter fundamentalmente aberto das ciências, restabelecendo outras lógicas discursivas e outras possibilidades de diálogos entre os conhecimentos disciplinares e os outros saberes, incluindo o filosófico e aqueles arraigados nas diferentes culturas humanas. Nas palavras de Prigogine: "chegou o tempo de novas alianças, desde sempre firmadas, durante muito tempo ignoradas, entre a história dos homens, de suas sociedades, de seus saberes, e a aventura exploradora da natureza". (PRIGOGINE, 1984)

Como pano de fundo, mas também como princípios agenciadores das mudanças de orientações no contexto das sociedades globais e locais, emergem as crises socioambientais, contaminadas pelo risco e cujo efeito reflexo induz estratégias práticas e teóricas, extrapolando os marcos da racionalidade científica. O campo dos conflitos sociais, ao permitir a emergência de novos sentidos sobre a natureza e as sociedades, permite a construção de outras estratégias cognitivas por parte dos atores sociais.

As novas epistemologias socioambientais emergentes são plurais e diferenciadas: ora buscando uma unidade íntima e indissolúvel entre natureza e sociedade; ora pensando a complexidade como referencial aproximador das ciências, ou ainda tratando de conhecer o que as ciências desconhecem, por meio da possibilidade de emergência do saber ambiental oriundo de saberes culturais arraigados - obrigando o próprio saber científico a abrir caminho para outras estratégias conceituais, fazendo apelo às diversidades enraizadas na cultura e nas identidades, ampliando assim o sentido prático e conceitual para uma nova educação socioambiental.

\section{Algumas idéias norteadoras para a construção de metodologias interdisciplinares em meio ambiente e desenvolvimento ${ }^{1}$}

Não há uma teoria geral dos "eventos interdisciplinares", a exemplo dos fenômenos que independem das interpretações. A interdisciplinaridade é um efeito do conhecimento sobre uma ordem de fenômenos. Mas não é um conhecimento que se limita ao resultado das disciplinas científicas, consideradas isoladamente uma das outras. Ao contrário, onde cessa o conhecimento disciplinar, começa a construção desse plus que não está dado de antemão. 
A discussão sobre interdisciplinaridade é objeto de constantes controvérsias, não havendo consenso sobre a mesma. O que se pode dizer sobre esse debate é que existem, grosso modo, duas visões diferenciadas: a primeira delas aproxima o diálogo entre disciplinas científicas, no intuito de ampliar a explicação dos objetos de conhecimento disciplinares, como no caso da bioinformática, que reúne diversas disciplinas afins; a segunda visão sobre a construção interdisciplinar restringe-se mais ao campo da pesquisa temática, opondo-se tanto à visão das assimilações progressivas entre disciplinas, como da justaposição de umas sobre outras. Essa visão reconhece a especificidade disciplinar, mas adota uma espécie de colaboração deliberada entre os saberes disciplinares, sobre temas previamente definidos (FLORIANI, 2004, p. 144). É nessa segunda visão que pode ser compreendida a interdisciplinaridade em pesquisas socioambientais, sobre a qual destacam-se os seguintes aspectos:

1 - no campo socioambiental, os fundamentos teóri$\cos$ da produção do conhecimento estão associados com metodologias alternativas, como da interdisciplinaridade, que é entendida como a articulação de diferentes disciplinas para melhor compreender e administrar situações de acomodação, tensão ou conflito explícito entre as necessidades humanas, as práticas sociais e as dinâmicas naturais;

2 - a noção de meio ambiente tende a ser multicêntrica, complexa e objeto de diferentes escalas de abordagem, devendo constituir um dos eixos centrais nos processos de desenvolvimento das sociedades. As temáticas sobre meio ambiente buscam interfaces com as dimensões sociais do desenvolvimento, não se restringindo ao conhecimento científico ou às atividades acadêmicas;

3 - no sentido estrito, porém, o campo da pesquisa interdisciplinar em meio ambiente pertence à construção sistemática do conhecimento, engajado com a história dos conhecimentos disciplinares e às suas práticas metodológicas;

4 - não há uma situação ideal de interdisciplinaridade. As diversas experiências desenvolvidas até agora nesse domínio são diferenciadas umas das outras, limitadas e em construção;

5 - deve-se procurar evitar a confusão entre processos sintéticos de construção individual do conhecimento (confundidos às vezes com delírios, alu- cinações ou surtos de onisciência!), com as práticas de elaboração e de metodologias de pesquisa, deliberadamente interdisciplinares, e que confrontam diversas disciplinas sobre uma mesma problemática socioambiental;

6 - a atitude interdisciplinar deliberada está apoiada em trocas intersubjetivas sistemáticas e coordenadas, por meio da troca permanente entre sujeitos da pesquisa, e sob o exercício do controle intersubjetivo da ação da pesquisa, a partir do confronto de saberes disciplinares, levando em conta a possibilidade de pesquisa sobre uma ou mais problemáticas de interface dos sistemas naturais e sociais;

7 - na interdisciplinaridade, o subjetivo se transforma em intersubjetivo e objetivo ao mesmo tempo, ocorrendo uma permuta entre subjetividades e múltiplos olhares deliberados na construção de objetividades. As disciplinas devem procurar trocar permanentemente suas experiências de pesquisa com as demais em presença, sem perderem suas respectivas identidades, incorporando questões que cada uma delas traz para o contexto das permutas da pesquisa. Ao longo do processo, as disciplinas acabarão incorporando questões novas para suas próprias lógicas disciplinares, o que dificilmente fariam se não estivessem inseridas no contexto interdisciplinar de pesquisa;

8 - a interdisciplinaridade na pesquisa não emerge espontaneamente dos diferentes saberes, exigindo uma reflexão profunda sobre diversas categorias de análise que emergem das novas epistemologias;

9 - genericamente, pode-se definir a experiência interdisciplinar como o confronto de diferentes saberes organizados ou disciplinares que, no âmbito do meio ambiente e do desenvolvimento, desenham estratégias de pesquisa, diferentes daquelas que faria cada saber por seu lado e fora dessa interação (FLORIANI, 1998, 2003);

10-não existindo de antemão, a prática interdisciplinar não emerge por decreto, mas é produto de uma associação disciplinar deliberada. Ocorrendo na fronteira dos conhecimentos disciplinares sobre natureza e sociedade, esse procedimento permite juntar diferentes domínios da realidade e separar as especificidades da mesma, captadas por diferentes disciplinas, e fazendo com esse duplo movimento uma nova síntese; 
11-poderia estar agregando a Décima Primeira Tese, em analogia com as teses de Marx sobre Feuerbach, sugerindo idéias de transformação, intervenção mas também de conflito, a saber, aquelas que derivam dos obstáculos, oposições e disputas abertas na cartografia dos saberes acadêmicos, apontando para o desenho cultural do fazer a partir do conhecer e do conhecer a partir do fazer.

\section{REFERÊECIAS}

FLORIANI, Dimas. Conhecimento, meio ambiente e globalização. Curitiba: Juruá-PNUMA, 2004. 176 p.

; KNECHTEL, Maria do Rosário. Educação ambiental - epistemologia e metodologias. Curitiba: Vicentina, 2003. $143 \mathrm{p}$.

GARCÍA, Rolando. Interdisciplinariedad y sistemas complejos. Ciencias Sociales y Formación Ambiental. Barcelona: Gedisa, 1994.
LEFF, Enrique. Saber ambiental, sustentabilidade, racionalidade, complexidade, poder. Petrópolis: Vozes, 2001.

PRIGOGINE, Ilya; STENGERS, Isabelle. A nova aliançametamorfose da ciência. Brasilia: UnB, 1984. 